\title{
Penerapan Akuntansi Zakat sebagai Respon Administrasi Digital di Era Modern: Studi pada Badan Amil Zakat Nasional (BAZNAS) Provinsi Jawa Timur
}

\author{
Miftakhul Munir \\ Sekolah Tinggi Ilmu Tarbiyah Pasuruan, Indonesia \\ miftakhulm55@gmail.com
}

Rizka Rahmatillah Zidna

Universitas Islam Negeri Sunan Ampel Surabaya, Indonesia

rrizkarahmatillah@gmail.com

\begin{abstract}
:
This study seeks to present ways or methods of applying accounting aspects in terms of controlling zakat administration, such as reports and institutional data. Administrative governance is an important thing to do, considering that zakat management requires valid, easy and clear data. Administrations such as finance, services, to reporting on institutional improvements require accounting to be more systematic and well-recorded. Because what has been a problem from the past until now, is the unification of the administration of zakat funds, it is still monotonous, rigid and manual. As a result, the required data is often not found. This has an impact on the effectiveness and development of the zakat institution itself. Therefore, by using a descriptive qualitative field study, this study will examine practically the application of zakat accounting for administrative regularity. The data collected comes from data about how zakat accounting works, hereinafter referred to as primary data. Primary data were collected through interview and documentation techniques with data analysis, reduction, editing and display. Data is only presented when it is final and there are no conflicts. From the research results, important things were found, namely 1) based on public accountants, PSAK No. 109, several policies made by BAZNAS East Java have not been realized. The reason for this problem is due to the ineffective management of zakat, infaq and shadaqah funds and the lack of adequate human resources in these business entities. 2) the method taken in completing it is to train and add quality human resources, especially in the accounting and finance departments. Then fix the information system at the accountant department.
\end{abstract}

Keywords: Promotion Strategy, Waqf, Waqf Insitution 


\section{Latar Belakang}

Sebagai Negara yang memiliki mayoritas penduduk muslim, Indonesia tentunya mempunyai potensi penghimpunan zakat dikarenakan dengan angka yang begitu besar dengan dibuktikan hasil dari sejumlah penelitian studi tentang potensi penghimpunan zakat pada lingkup nasional hingga mencapai angka 230 triliun rupiah. ${ }^{1}$ Penghimpunan dana BAZNAS meningkat setiap tahunnya, dan hal ini menunjukkan akan meningkatnya tingkat kesadaran tiap masyarakat untuk membayar zakat. ${ }^{2}$ Namun demikian, upaya dalam peningkatan penghimpunan dana zakat dan infak maupun sedekah masih terus dievaluasi agar kesadaran dan kedisiplinan masyarakat dalam pembayaran zakat dengan lebih efektif.

Menyadari atas pentingnya peran organisasi pengelola zakat dalam mengelola dana zakat dan infak/sedekah, pemerintah mengaluarkan standar peraturan manajemen dana infaq dan zakat dalam UU Nomor 38 Tahun 1999. Lalu, dengan pedoman pelaksanaannya pada PP (peraturan pemerintah) No. 14 tahun 2014. Selain kedua aturan tersebut yang harus diikuti oleh seluruh organisasi pengelola zakat, juga ada aturan untuk mencatat akuntansi yang sudah diatur pada Pernyataan Standar Akuntansi keuangan (PSAK) No. 109 yang dimakbulkan oleh Ikatan Akuntan Indonesia (IAI) dan resmi diberlakukan pada 6 April 2010. ${ }^{3}$

Penelitian pada Badan Amil Zakat Nasional Provinsi Jawa Timur yang diteliti oleh Lathifah (2012) menyebukan bahwa Badan Amil Zakat Nasional Provinsi Jawa Timur pada saat itu secara keseluruhan belum sepenuhnya mempraktikkan akuntansi standar secara universal dan bentuk laporan yang sudah diatur pada PSAK No. 109.4 Sedangkan pada penelitian Dewi (2018) menyatakan bahwa Badan Amil Zakat Nasional

\footnotetext{
${ }^{1}$ Lihat dalam penelitian Wahib Aziz (2017) bahwa penghimpunan dana zakat dan wakaf jika maksimal dikelola dan dihimpun dengan tepat, dapat membantu negara atau bahkan lebih efektif untuk mengurangi kemiskinan dan ketertinggalan mayarakat miskin. Beberapa negara, dan bahkan secara historis, telah membuktikan bahwa dana zakat mampu berbicara banyak untuk mengentaskan kemiskinan, sehingga akhir-akhir ini negara melirik dana zakat untuk dijadikan mitra dengan sebutan sukuk. Jumlah masyarakat muslim yang mayoritas, serta ra-rata bearada pada ekonomi mampu, bukan tidak mungkin jika upayanya maksimal, lembaga zakat mampu menghilankan kemiskinan di negeri ini. Lihat M. Wahib Aziz, "Wakaf Tunai dalam Perspektif Hukum Islam”, International Journal Ihya' al-Din, 19, 1(2017): 1-23.

${ }^{2}$ Lihat dalam laporan National Zakat Statistik tiga tahun terakhir yang melaporkan pada tahun 2018 ke 2019 naik sekitar 26\% dan pada 2020 naik 23\%. Periksa dalam situs pid.baznas.go.id tentang statistik Baznas sejak tahun 2018-2020.

${ }^{3}$ Carolina Lita Permatasari; Heri yanto; Widyanto, "Penerimaan Pernyataan Standar Akuntansi Keungan oleh Pengelola Keuangan Yayasan Pendidikan: Analisis Technology Acceptance Model", JEE: Journal of Economic Education, 5, 1(2016): 90-92.

${ }^{4}$ Ana Toni Roby Candra Yudha; Nurul Lathifah, "Productive Zakat as a Fiscal Element for the Development and Empowerment of Micro Enterprises in East Java Province", International Conference of Zakat, https://doi.org/https://doi.org/10.37706/iconz.2018.123.
} 
Kabupaten Bojonegoro masih sedikit belum memenuhi kriteria dalam penerapan Pernyataan Standar Akuntansi keuangan (PSAK) No. 109 yang diterbitkan oleh IAI tentang standar zakat akuntansi. ${ }^{5}$

Maka diambil dari kejadian tersebut akan dilakukan penelitian terhadap penerapan akuntansi zakat dan infak / sedekah pada badan amil zakat nasional (BAZNAZ) Provinsi Jawa Timur dikarenakan sangat tidaklah mungkin bahwa potensi dana zakat bia terkumpul dan dikelola (manage) dengan maksimal tanpa diterapkannya mekanisme dan pencatatan yang sesuai dengan peraturan yang telah ditentukan. Berdasar kepada data yang sudah dikumpulkan, hasil nlai Indeks Zakat Nasional BAZNAS Provinsi Jawa Timur menunjukkan peningkatan pada tahun ini dari angka 0,59 (cukup baik) sehingga menjadi sebesar 0,66 (baik), dengan nilai yang didapatkan melalui penimbangan dimensi makro dan mikro. Sebagaimana dijelaskan di bawah ini.

\section{Gambar 1.1}

Nilai Indeks Zakat Nasional OPZ di Provinsi Jawa Timur

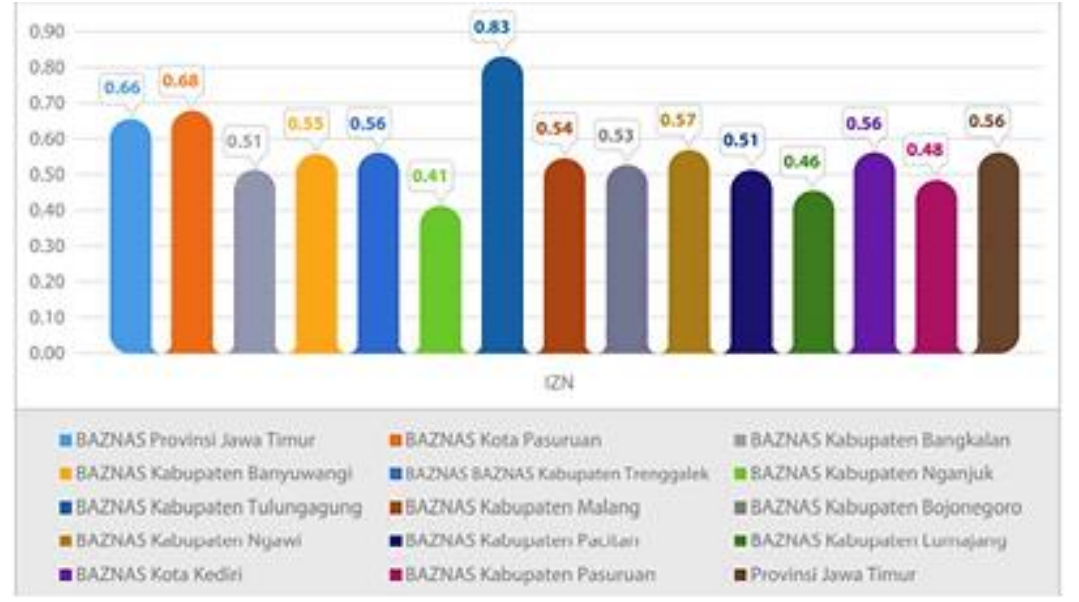

\begin{tabular}{|c|c|c|c|c|}
\hline Variabel & Indeks & Indikator & Indeks & Dimensi \\
\hline Regulasi Daerah & 1,00 & Regulasi & 1,00 & \multirow{5}{*}{$\begin{array}{c}\text { Makro } \\
0,48\end{array}$} \\
\hline Dukungan APBD untuk BAZNAS & 0,25 & $\begin{array}{c}\text { Dukungan APBD untuk } \\
\text { BAZNAS }\end{array}$ & 0,25 & \\
\hline $\begin{array}{l}\text { Jumlah lembaga zakat resmi, muzaki } \\
\text { dan mustahik }\end{array}$ & 0,75 & \multirow{3}{*}{ Database lembaga zakat } & \multirow{3}{*}{0,25} & \\
\hline $\begin{array}{l}\text { Rasio jumlah muzaki individu terhadap } \\
\text { rumah tangga di tingkat provinsi }\end{array}$ & 0,00 & & & \\
\hline $\begin{array}{l}\text { Rasio jumlah muzaki badan usaha } \\
\text { terhadap jumlah badan usaha di tingkat } \\
\text { provinsi }\end{array}$ & 0,00 & & & \\
\hline
\end{tabular}

5 DSAK IAI. Pernyataan Standar Akuntansi Keuangan No. 109 Akuntansi Zakat dan Infak/ Sedekah. (Jakarta: IAI, 2011), 56-68. 


\begin{tabular}{lcccc|}
\hline \multicolumn{1}{|c}{ Variabel } & Indeks & Indikator & Indeks & Dimensi \\
\hline Penghimpunan & 0,75 & & & \\
\hline Pengelolaan & 0,75 & & & \\
\hline Penyaluran & 0,81 & Kelembagaan & 0,82 & \\
\hline Pelaporan & 1,00 & & & 0,78 \\
\hline Indeks Kesejahteraan CIBEST & 1,00 & & & \\
\hline Modifikasi IPM & 0,50 & Dampak Zakat & 0,75 & \\
\hline Kemandirian & 0,76 & & & \\
\hline
\end{tabular}

Sumber: Pusat Kajian Strategis Badan Amil Zakat Nasional.

Dari tiga tabel diatas, dapat dijelaskan bahwa indeks zakat di Propinsi Jawa Timur mengalami peningkatan signifikan setiap tahun. Ini menghilustrasikan bahwa dibutuhkan akuntansi zakat yang sistematis untuk mendapatkan asministrasi yang benar. Oleh karena dasar itulah, peneliti tergerak untuk melakukan penelitian di Baznas Jawa Timur tentang penerapan akuntasi zakat.

\section{Kajian Teori}

\section{Transparansi Organisasi}

Transparansi adalah suatu keterbukaan pemerintah dalam menyampaikan suatu informasi terkait aktivitas manajemen sumberdaya public kepada beberapa pihak yang membutuhkan informasi (Mardiasmo, 2001). Implementasi dari teori transparasi pada penelitian ini adalah bahwa BAZNAS (Badan Amil Zakat Nasional) memiliki keharusan untuk memiliki detail atas pengelolaan keuangan berdasar dengan peraturan undang-undang, melaksanakan pencatatan kepada setiap transaksi yang mengelola dana infaq dan zakat dengan mematuhi tolak ukur akuntansi keuangan yang telah diberlakukan, dan adanya keterbukaan informasi yang mudah dipahami masyarakat.

Dalam suatu organisasi, baik pemerintah maupun non pemerintah, diperlukan adanya keterbukaan informasi agar dapat diakses oleh pencari informasi atau stakeholders, keterbukaan difungsikan untuk mengawasi kinerja organisasi tersebut. Beberapa butir aturan perundang-undangan dibuat untuk melindungi dan mengawal transparansi organisasi yakni UU Nomor 14 tahun 2008 tentang Keterbukaan Informasi Publik (KIP). UU ini mengharuskan adanya transparansi terhadap seluruh data organisai, kecuali menyangkut rahasia organisasi. ${ }^{6}$

\footnotetext{
${ }^{6}$ Farid Hamid; Heri Budianto, Ilmu Komunikasi: Sekarang dan Tantangan Masa Depan. (Jakarta: Kencana Prenada Media Group, 2011), 331.
} 
Bahkan, dari saking pentingnya transparansi dalam organisasi, dimasukan pada unsur Good Governance, sebagai bagian dari kesehatan organisasi. Prinsip transparansi dibangun atas dasar kebebasan dan terbuka untuk publik baik secara langsung atau tidak. ${ }^{7}$ Hal ini dikuatkan oleh Peraturan Pemerintah Nomor 24 tahun 2005 yang menyiratkan bahwa fungsi transparansi adalah untuk memberikan informasi penting kepada stakeholder berdasarkan pertimbangan-pertimbangan secara menyeluruh, bersifat bebes dan tidak terikat. Karenanya, transparansi merupakan bagian penting dalam kemajuan organisasi. ${ }^{8}$

Mardiasmo dalam Muhammad Rizki Syahri Romdhon memaparkan tentang indikator transparansi setelah disaring dari berbagai pendapat ahli, yaitu: 1) adanya informasi bebas akses tentang pendapatan, keuangan, pengelolaan dan aset, 2) seluruh data mulai dari laporan pendapatan, keuangan dan aset pengembangan organisasi mudah diakses, 3) adanya laporan pertanggungjawaban yang temporal, 4) adanya sarana khusus aspirasi dari stakeholders, 5) tersedia sistem atau ruang informasi. ${ }^{9}$ Indikator ini menyiratkan bahwa beberapa data yang diperlukan dalam rangka transaparansi data adalah laporan berupa pendapatan keuangan, pengeluaran keuangan, aset organisasi dan produk organisasi yang berupa program. Di luar itu, tidak temasuk pada laporan yang harus terbuka. Transparansi inilah yang membutuhkan cara dan skill yang disebut dengan akuntansi.

\section{Tinjauan Konsep Zakat}

Zakat didefinisikan kedalam dua aspek yaitu definisi zakat dari segi bahasa dan dari segi hukum syariah. Dalam aspek bahasa, zakat memiliki kata dasar "zaka" yang bermakna pertumbuhan, pensucian,dan berkah. Setiap sesuau yang bertambah jumlahnya maupun berkembang ukurannya dinamakan zakat. ${ }^{10}$ Dari segi hukum syariah zakat adalah nama bagi sejumlah harta tertntu yang telah mencapai suatu syarat yang diwajibkan oleh Allah SWT untuk dikeluarkan dan diberikan kepada pihak pihak yang berhak menerimanya dengan klasifikasi yang sudah ditetapkan dalam surat at-Taubah ayat 103

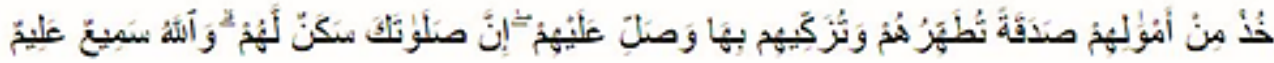

\footnotetext{
${ }^{7}$ Hery, Teori Akuntansi. (Jakarta: Kencana Prenada Media Group, 2009), 114

${ }^{8}$ Djarwanto, Pokok-Pokok Analisa Laporan Keuangan. (Yogyakarta: BPFE, 1997), 17

${ }^{9}$ Zaki Baridwan, Intermediate Accounting. (Yogyakarta: BPFE, 2008), 17.

${ }^{10}$ Yandi Bastiar; Efri Syamsul Bahri, "Model Pengukuran Kinerja Lembaga Zakat di Indonesia", Ziswaf: 6, 1(2019): 43-63.
} 
"Ambillah zakat dari harta mereka, guna membersihkan (kekiran dan cinta yang berlebih terhadap harta) dan menyucikan (zakat menyuburkan sifat kebaikan dalam hati mereka dan menggandakan harta bagi mereka). Sesungguhnya doamu itu menumbuhkan ketentraman jiwa bagi mereka. Allah maha pendengar, Maha mengetahui."

Menurut Hamdan Rasyid, sebagaimana dikutip oleh Rizaldi dkk (2020) bahwa dalam Al Quran kata zakat telah disebut sebanyak 32 kali dan sebagian itu beriringan dengan kata shalat. Bahkan jika digabungkan dengan perintah untuk memberi infak, sedekah untuk kebajikan serta memberi makan orang fakir dan miskin maka jumlahnya akan menjadi 115 kali disebutkan dalam Al Quran. ${ }^{11}$

Infak merupakan sebagian asset atau benda yang telah diserahkan dari seseorang maupun sebuah badan usaha. infak berasal dari kata anfaqa yang mempunyai makna mengeluarkan sesuatu (harta) untuk kepentingan sesuatu. Infak adalah pengeluaran secara sukarela yang dilakukan seseorang, setiap kali ia mendapatkan rizki sebanyak yang ia kehendaki. Infak berlainan dengan zakat yang memahami nishab dan jumlah kekayaan yang dicatat secara hukum, melainkan nfak tidak harus dikeluarkan kepada mustahik (penerima) tertentu seperti pada zakat, baik orangtua, anak yatim, keraabat, dan lain sebagainya. Infak diklasifikasikan dalam dua jenis yaitu zakat wajib (zakat, nadzar,kafarat) dan zakat sunnah (infak yang diberikan epada sesama muslim, kemanusiaan, dan bencana alam). Lalu yang terakhir yaitu sedekah, sedekah adalah suatu kegiatan yang berorientasi sama dengan infak namun hukum didalamnya hanyalah Sunnah dan tidak ada kewajiban atas mengeluarkannya. ${ }^{12}$

Zakat fitrah adalah sejumlah bahan makanan pokok dikeluarkan pada saat bulan Ramadhan sebelum terlaksananya shalat idul fitri. Menurut Permenag RI nomor 52 tahun 2014, zakat fitrah dapat berupa beras(makanan pokok) atau bisa diganti dengan uang yang setara dengan beras tersebut. Syarat wajib bagi orang yang mengeluarkan zakat fitrah yakni memiliki agama islam, menjalankan bulan Ramadhan (masih hidup saat bulan Ramadhan), dan memiliki limpahan kebutuhan pokok berlebih pada saat malam dan hari raya idul fitri. ${ }^{13}$

${ }^{11}$ Rizaldi Yusfiarto; Ananda Setiawan; Spty Setia Nugraha, "Literacy and Intention to Pay Zakat: a Theory Planned Behavior View Evidence from Indonesian Muzakki”, International Journal of Zakat, 5,1(2020): 15-27.

12 F.I. Afiyana dkk., "Tantangan Pengelolaan Dana Zakat di Indonesia dan Literasi Zakat", Akuntebel, 1,6(2019): 222-223.

${ }^{13}$ Lihat dalam Baznas, Indeks Literasi Zakat: Teori dan Konsep. (Jakarta: Pusat Kajian Strategis Badan AMil Zakat Nasional, 2019), 55.56. 
Zakat mal merupakan harta yang bisa dibayarkan pada waktu yang tidak tertentu, yakni harta yang dimiliki muzakki perseorangan dengan tanda kutib milik orang tersebut secara penuh, berkembang, cukup nishab, lebih dari kebutuhan pokok, terbebas hutang, sudah berjalan lebih setahun (haul). Harta yang dikenakan zakat antara lain yaitu emas, perak, serta logam mulia yang lainnya, uang dan surat surat berharga, perniagaaan, perkebunan dan kehutanan, peternakanndan perikanan, pertambangan, perindustrian, pendapatan/jasa, dan rikaz. Objek zakat maal serta perhitungannya akan dijelaskan pada tabel.

Tabel 1.2

Zakat Maal beserta penghitungannya

\begin{tabular}{|c|c|c|c|c|c|}
\hline \multirow[t]{2}{*}{ No. } & \multirow[t]{2}{*}{ Jenis Harta } & \multicolumn{3}{|c|}{ Ketentuan Wajib Zakat } & \multirow[t]{2}{*}{ Keterangan } \\
\hline & & Nisab & Kadar & Waktu & \\
\hline 1. & Emas (murni) & $\begin{array}{c}\text { Senilai 91,922 } \\
\text { gram emas murni }\end{array}$ & $2,5 \%$ & Setiap Tahun & $\begin{array}{c}\text { Menurut madzhab } \\
\text { Hanafi, nisabnya } \\
\text { senilai 107,76 gr. } \\
\text { Menurut Yusuf Al } \\
\text { Qardagi, nisabnya } \\
\text { senilai } 85 \text { gr. }\end{array}$ \\
\hline 2. & $\begin{array}{c}\text { Perhiasan } \\
\text { perabotan/ } \\
\text { perlengkapan } \\
\text { rumah tangga } \\
\text { berbahan baku } \\
\text { emas. }\end{array}$ & $\begin{array}{c}\text { Senilai 91,922 } \\
\text { gram emas murni }\end{array}$ & $2,5 \%$ & Setiap Tahun & $\begin{array}{c}\text { Menurut madzhab } \\
\text { Hanafi, nisabnya } \\
\text { senilai 107,76 gr. } \\
\text { Menurut Yusuf Al } \\
\text { Qardagi, nisabnya } \\
\text { senilai } 85 \\
\text { gr.Perhiasan yang } \\
\text { dipakai dalam } \\
\text { ukuran yang wajar } \\
\text { dan halal menurut } \\
\text { madzhab Maliki, } \\
\text { Syafi'I, dan } \\
\text { Hambali tidak wajib } \\
\text { dizakati. }\end{array}$ \\
\hline 3. & Perak & $\begin{array}{l}\text { Senilai } 642 \text { gram } \\
\text { emas perak }\end{array}$ & $2,5 \%$ & Setiap Tahun & $\begin{array}{c}\text { Menurut mazhab } \\
\text { Hanafi, nisabnya } \\
\text { senilai } 700 \mathrm{gr}\end{array}$ \\
\hline 4. & $\begin{array}{c}\text { Perhiasan } \\
\text { perabotan/ } \\
\text { perlengkapan }\end{array}$ & $\begin{array}{c}\text { Senilai } 642 \text { gram } \\
\text { emas perak }\end{array}$ & $2,5 \%$ & Setiap Tahun & $\begin{array}{l}\text { Menurut mazhab } \\
\text { Hanafi, nisabnya } \\
\text { senilai } 700 \text { gr. }\end{array}$ \\
\hline
\end{tabular}




\begin{tabular}{|c|c|c|c|c|c|}
\hline & $\begin{array}{c}\text { rumah tangga } \\
\text { berbahan baku } \\
\text { perak. }\end{array}$ & & & & $\begin{array}{c}\text { Perhiasan yang } \\
\text { dipakai dalam } \\
\text { ukuran yang wajar } \\
\text { dan halal menurut } \\
\text { madzhab Maliki, } \\
\text { Syafi'I, dan } \\
\text { Hambali tidak wajib } \\
\text { dizakati. }\end{array}$ \\
\hline 5. & $\begin{array}{l}\text { Logam selain } \\
\text { yang berbahan } \\
\text { baku emas dam } \\
\text { perak. Contoh: } \\
\text { platina, dsb. }\end{array}$ & $\begin{array}{c}\text { Senilai 91,922 } \\
\text { gram emas murni }\end{array}$ & $2,5 \%$ & Setiap Tahun & $\begin{array}{l}\text { Menurut madzhab } \\
\text { Maliki, Syafi'I, dan } \\
\text { Hambali wajib } \\
\text { mengeluarkan zakat } \\
\text { apabila masuk } \\
\text { dalam kategori } \\
\text { zakat perdagangan. }\end{array}$ \\
\hline 6. & $\begin{array}{l}\text { Industri } \\
\text { seperti pupuk, } \\
\text { semen, } \\
\text { tekstil,dsb }\end{array}$ & $\begin{array}{c}\text { Senilai } 91,922 \\
\text { gram emas murni }\end{array}$ & $2,5 \%$ & Setiap Tahun & $\begin{array}{c}\text { Menurut madzhab } \\
\text { Hanafi, nisabnya } \\
\text { senilai 107,76 gr. } \\
\text { Menurut Yusuf Al } \\
\text { Qardagi, nisabnya } \\
\text { senilai } 85 \text { gr. }\end{array}$ \\
\hline 7. & $\begin{array}{l}\text { Batu permata. } \\
\text { Contoh: intan } \\
\text { berlian,dsb }\end{array}$ & $\begin{array}{c}\text { Senilai } 91,922 \\
\text { gram emas murni }\end{array}$ & $2,5 \%$ & Setiap Tahun & $\begin{array}{l}\text { Menurut madzhab } \\
\text { Maliki, Syafi'I, dan } \\
\text { Hambali wajib } \\
\text { mengeluarkan zakat } \\
\text { apabila masuk } \\
\text { dalam kategori } \\
\text { zakat perdagangan. }\end{array}$ \\
\hline 8. & $\begin{array}{l}\text { Perdagangan } \\
\text { seperti } \\
\text { kontraktor, real } \\
\text { estate, } \\
\text { perdagangan } \\
\text { luar negeri, } \\
\text { percetakan, } \\
\text { supermarket, } \\
\text { dsb. }\end{array}$ & $\begin{array}{c}\text { Senilai } 91,922 \\
\text { gram emas murni }\end{array}$ & $2,5 \%$ & Setiap Tahun & $\begin{array}{l}\text { Menurut madzhab } \\
\text { Hanafi, nisabnya } \\
\text { senilai 107,76 gr. } \\
\text { Menurut Yusuf Al } \\
\text { Qardagi, nisabnya } \\
\text { senilai } 85 \text { gr. }\end{array}$ \\
\hline 9. & $\begin{array}{l}\text { Usaha restoran, } \\
\text { hiburan, } \\
\text { perhotelan, dsb. }\end{array}$ & $\begin{array}{c}\text { Senilai 91,922 } \\
\text { gram emas murni }\end{array}$ & $2,5 \%$ & Setiap Tahun & $\begin{array}{c}\text { Menurut madzhab } \\
\text { Hanafi, nisabnya } \\
\text { senilai 107,76 gr. }\end{array}$ \\
\hline
\end{tabular}




\begin{tabular}{|c|c|c|c|c|c|}
\hline & & & & & $\begin{array}{c}\text { Menurut Yusuf Al } \\
\text { Qardagi, nisabnya } \\
\text { senilai } 85 \text { gr. }\end{array}$ \\
\hline 10. & $\begin{array}{c}\text { Pendapatan gaji } \\
\text { dan sejenisnya }\end{array}$ & $\begin{array}{c}\text { Senilai } 91,922 \\
\text { gram emas murni }\end{array}$ & $2,5 \%$ & Setiap Tahun & $\begin{array}{l}\text { Menurut madzhab } \\
\text { Hanafi, nisabnya } \\
\text { senilai 107,76 gr. } \\
\text { Menurut Yusuf Al } \\
\text { Qardagi, nisabnya } \\
\text { senilai } 85 \text { gr. }\end{array}$ \\
\hline 11. & $\begin{array}{c}\text { Perusahaan } \\
\text { jasa. Contoh: } \\
\text { notaris, } \\
\text { konsultan, dsb }\end{array}$ & $\begin{array}{c}\text { Senilai 91,922 } \\
\text { gram emas murni }\end{array}$ & $2,5 \%$ & Setiap Tahun & $\begin{array}{c}\text { Menurut madzhab } \\
\text { Hanafi, nisabnya } \\
\text { senilai 107,76 gr. } \\
\text { Menurut Yusuf Al } \\
\text { Qardagi, nisabnya } \\
\text { senilai } 85 \text { gr }\end{array}$ \\
\hline 12. & $\begin{array}{c}\text { Usaha } \\
\text { perikanan, } \\
\text { perkebunan, } \\
\text { dan sektor } \\
\text { lainnya }\end{array}$ & $\begin{array}{c}\text { Senilai 91,922 } \\
\text { gram emas murni }\end{array}$ & $2,5 \%$ & Setiap Tahun & $\begin{array}{c}\text { Menurut madzhab } \\
\text { Hanafi, nisabnya } \\
\text { senilai 107,76 gr. } \\
\text { Menurut Yusuf Al } \\
\text { Qardagi, nisabnya } \\
\text { senilai } 85 \text { gr }\end{array}$ \\
\hline 13. & $\begin{array}{l}\text { Simpanan, } \\
\text { deposito,giro, } \\
\text { dsb. }\end{array}$ & $\begin{array}{c}\text { Senilai 91,922 } \\
\text { gram emas murni }\end{array}$ & $2,5 \%$ & Setiap Tahun & $\begin{array}{c}\text { Menurut madzhab } \\
\text { Hanafi, nisabnya } \\
\text { senilai 107,76 gr. } \\
\text { Menurut Yusuf Al } \\
\text { Qardagi, nisabnya } \\
\text { senilai } 85 \text { gr }\end{array}$ \\
\hline
\end{tabular}

Sumber: diolah dari berbagai literatur

\section{Organisasi Pengelola Zakat}

Organisasi pengelola zakat (OPZ) yakni sebuah institusi yang bertugas dalam bidang zakat, infak, dan sedekah. UU No. 23 Tahun 2011 menyebutkan bahwa lembaga pengelola zakat terdiri atas dua macam organisasi pengelolaan zakat, yaitu

1) Badan Amil Zakat Nasional (BAZNAS)

Badan amil zakat yang dibentuk oleh pemerintah dan merupakan lembaga pemerintah yang bersifat non stuktural yang bersifat mandiri serta bertanggung jawab kepada presiden melalui menteri. Disamping bertugas mengelola zakat secara nasional, 
BAZNAS adalah yang menerbitkan rekomendasi izin pendirian LAZ yang diusulkan oleh badan hukum. ${ }^{14}$

2) Lembaga Amil Zakat (LAZ).

Untuk membantu BAZNAS dalam pelaksaan mengumpulan, distribusi, dan pendayagunaan zakat, masyarakat dapat membentuk lembaga amil zakat (LAZ). Lembaga amil zakat yakni organisasi masyarakat muslim yang bergerak dalam bidag social serta pendikikan dakwah yang didirikan atas kehendak masyarakat tersebut dan nantinya disahkan oleh pemerintah. LAZ wajib melaporkan semua kegiatan yang ada termasuk pengumpulan, pendistribusian, dan pendayagunaan zakat yang telah di audit kepada BAZNAS secara berkala. ${ }^{15}$

\section{Standar Akuntansi: PSAK No. 109}

Akuntansi zakat didefinisikan sebagai proses pengakuan, pengukuran, penyajian dan penganalisaan dana zakat dan infak/sedekah sesuai hukum syari yang berlaku yang bertujuan untuk menyajikan informasi pengelolaan dari zakat dan infak/sedekah kepada orang yang berhak menerima untuk tercapainya akuntabilitas, adanya transparansi, serta tanggung jawab. Disebutkan oleh Fajar Laksana tujuan lainnya dari akuntansi zakat menurut AAS-IFI Accounting and Auditing Standart for Islamic Financial Institution adalah memberikan informasi tentang ketaatan suatu organisasi terhadap syariat islam serta informasi yang berisi pengeluaaran dan penerimaan yang dilarang oleh ketentuan syariat islam yang apabila terjadi, dan penyalurannya. ${ }^{16}$

Mengacu kepada tujuan tersebut, terlihat bahwa peran Dewan Syariah dalam mengeluarkan opini syariah itu sangat krusial. Akuntansi pada dasarnya merupakan salahsatu bagian yang selalu dikaji dalam islam yang berarti makna dari akuntansi itu sendiri diserahkan kepada pola pikir manusia yang nantinya akan dikembangkan, sehingga dari itu semua dapat disimpulkan bahwa nilai nilai keislaman ada dalam akuntansi dan akuntansi ada dalam struktur hukum dan muamalat dalam islam. ${ }^{17}$

\footnotetext{
${ }^{14}$ Muhammad Rheza Ramadhan, "Integrasi Pajak dan Zakat di Indonesia”, Islamiconomic: Jurnal Ekonomi Islam, 8, 1(2017): 77-94.

${ }^{15}$ Muhammad Nhasifudin, "Konsep Sistem Pengelolaan Zakat di Indonesia Pengentas Kemiskinan Pendekatan Sejarah”, JE: Jurnal Ekonomi Syariah Indonesia, 5,2(2015): 219-231.

16 Taufikur Rahman, "Akuntansi Zakat, Infak dan Sedekah (PSAK 109) : Upaya Peningkatan transpran Akuntabilitas Organisasi Pengelola Zakat (OPZ)", Muqtasid: Journal of Islamic Economics and Baniking, 6,1(2015): 141-164.

17 Sabrina Shahnaz, "Penerapan PSAK No. 109 tentang Pelaporan Keuangan Akuntansi Zakat, Infaq/sedekah pada Badan Amil Zakat Provinsi Sulawesi Utara”, Jurnal Emba: Jurnal Rset Ekonomi, Manajemen, Bisnis dan Akuntansi, 3,4(2015): 43.
} 
Lembaga amil zakat dalam mengumpulkan serta menyalurkan zakatnya menganut PSAK No. 109 pada standar akuntansi zakat, infak, serta sedekah dalam IAI Ikatan Akuntansi Indonesia yang dikeluarkan oleh IAI pada tanggal 26 februari 2008. Tujuan laporan pada PSAK No. 109 yakni semua lembaga amil zakat mempunyai acuan dalam mengelola laporan keuangan, mengatur bagaimana lembaga amil itu sendiri dalam pengakuan, pengukuran, pengungkapan, serta pelaporan. Perlakuan dalam PSAK No. 109 yakni sebagai berikut :18

Tabel 1.3

Perlakuan PSAK No. 109

\begin{tabular}{|c|c|c|}
\hline No. & Keterangan & PSAK No. 109 (Akuntansi Zakat dan Infak/Sedekah) \\
\hline \multirow[t]{4}{*}{1} & $\begin{array}{l}\text { Pengakuan } \\
\text { Zakat }\end{array}$ & a. Zakat yang diakui saat kas maupun asset lainnya telah diterima. \\
\hline & & $\begin{array}{l}\text { b. Zakat yang telah diterima, diakui menjadi penambahan dana } \\
\text { zakat sebesar nilai } \\
\quad \text { kas yang telah diterima/jika pada aset non kas sebesar nilai wajar. }\end{array}$ \\
\hline & & $\begin{array}{l}\text { c. Zaka disalurkan pada mustahik dianggap menjadi pengurangan } \\
\text { pada dana zakat. }\end{array}$ \\
\hline & & $\begin{array}{l}\text { d. Sebuah penerimaan ujrah dari Muzakki diakui menjadi } \\
\text { dana Amil. }\end{array}$ \\
\hline \multirow[t]{2}{*}{2} & \multirow[t]{2}{*}{$\begin{array}{l}\text { Pengakuan } \\
\text { Infak/Sedeka } \\
\text { h }\end{array}$} & $\begin{array}{l}\text { a. Infak/Sedekah nantinya menjadi dana infak/sedekah terikat } \\
\text { maupun tidak sesuai } \\
\text { dengan tujuan awal pemberi, diakui menjadi penambahan dana } \\
\text { infak/sedekah } \\
\text { sebesar nilai kas yang telah diterima/jika pada aset non kas } \\
\text { sebesar nilai wajar. }\end{array}$ \\
\hline & & $\begin{array}{l}\text { b. Penerimaan dana Infak/Sedekah di akui menjadi dana amil, dana } \\
\text { Infak/Sedekah } \\
\quad \text { khusus bagian penerima besaran presentase nantinya diatur oleh }\end{array}$ \\
\hline
\end{tabular}

${ }^{18}$ Taufikur Rahman, “Akuntansi Zakat, Infak dan Sedekah (PSAK 109), 154. 


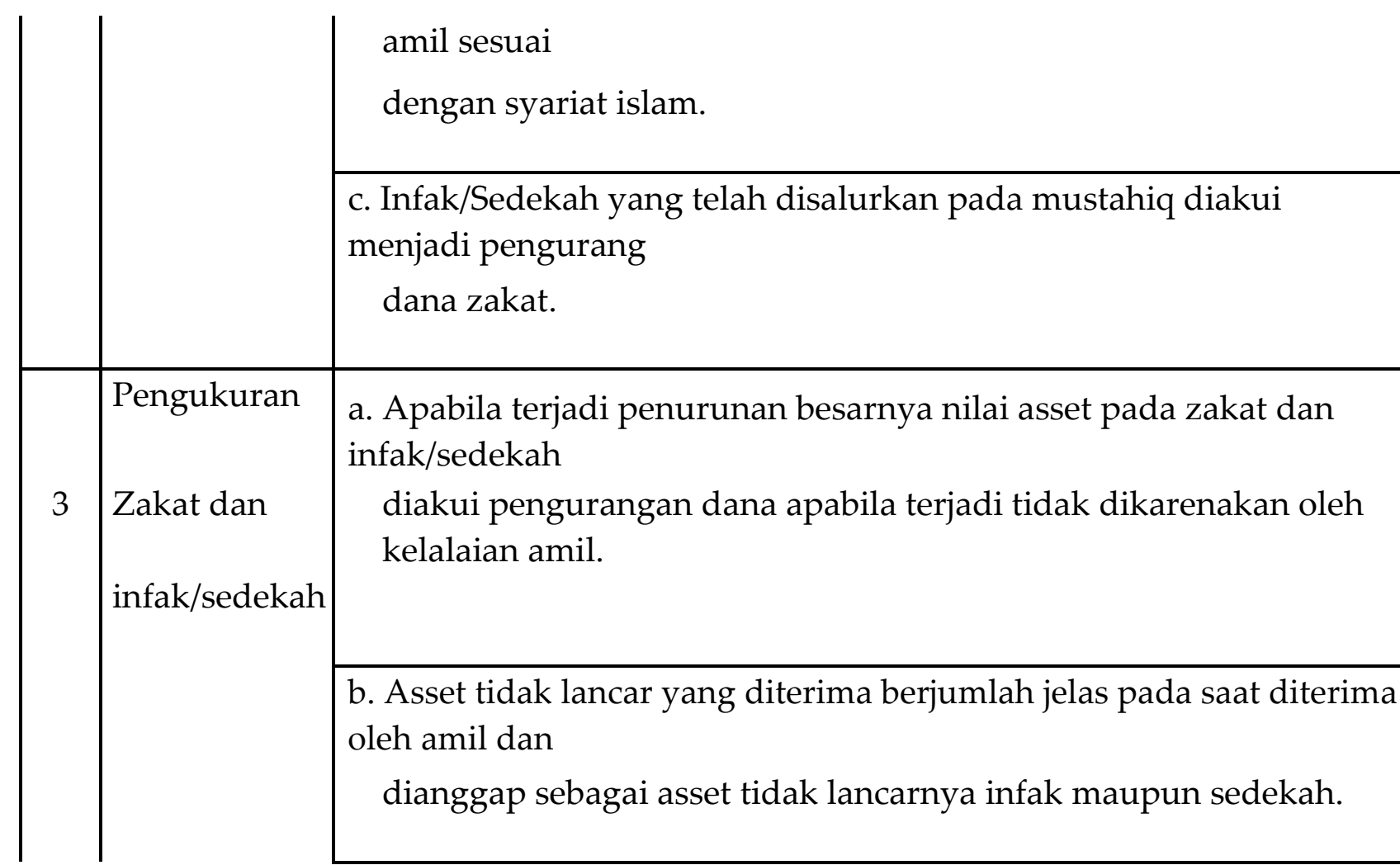

\section{Metode Penelitian}

Penelitian yang dilakukan oleh peneliti, menggunakan metode kualitatif deskriptif. Dimana pada penelitian ini bertujuan agar ditemukannya fakta dan realita yang ada, dengan memproses hasil olahan data yang bersangkutan dengan situasi yang sedang diteliti. Metode deskriptif adalah suatu metode yang diperuntukkan guna memapaparkan serta memberikan gambaran terhadap obyek yang sedang diteliti melalui metadata dan beberapa sampel yang telah terkumpul yang selanjutnya dilakukan analisis dan membuat kesimpulan yang berlaku untuk umum. ${ }^{19}$

Dengan menganalisis sejumlah data yang telah digali, data yang digunakan oleh penulis merupakan primary data (data primer) dan secondary daya (data sekunder), ${ }^{20}$ yang pada kali ini data primer diperoleh dengan cara interview virtual bersama salahsatu staff BAZNAS Jawa Timur. mengenai bagaimana penerapan akuntansi zakat dan infak/sedekah. Serta data sekunder didapatkan dari beberapa berkas penunjang seperti literature, artikel ilmiah, buku-buku, serta beberapa data yang berkorelasi dengan penelitian ini.

\footnotetext{
${ }^{19}$ Lexy J. Moleong, Metodologi Penelitian Kualitatif, (Bandung: Remaja Rosdakarya, 2014), 157 158.

${ }^{20}$ Sugiyono, Metode Penelitian Kuantitatif Kualitatif dan R \& D (Bandung: Alfabeta, 2014), 246.
} 
Dalam menganalisis data, sistematika kualitatif ${ }^{21}$ dilakukan oleh sang penulis dengan mendeskripsikan atau menjabarkan secara detail bagaimana fenomena beserta fakta pada penerapan akuntansi zakat dan infak/sedekah yang diterapkan selama ini. Kemudian daripada itu dari fenomena yang telah ditemukan akan dikomparasikan bersama tatanan yang ada pada sitematika yang ada. Dalam penelitian ini, fenomena dan fakta yang ditemukan pada BAZNAS provinsi Jawa Timur akan ditabulasikan serta akan dikomparasi dengan tatanan yang ada pada PSAK 109.

\section{Hasil Penelitian}

\section{Manajemen Dana ZIS pada BAZNAS Provinsi Jawa Timur}

BAZNAS Provinsi Jawa Timur merupakan organisasi pengelolaan zakat yang beroperasi di Jawa Timur sejak tahun 1991 dengan disahkan dengan surat keputusan bersama antara Mentri agama dan Mentri dalam Negeri no. 29 Tahun 1991 dan no. 47 tahun 1991. Selain hal tersebut, Badan Amil Zakat Nasional (BAZNAS) Provinsi Jawa Timur, secara operasional telah mendapat lisensi izin dengan disahkannya pada tanggal 3 Juli 1992 bertempat di Jl. Raya Dukuh Kupang / 122-144 Surabaya. Visi dari Baznas jatim yaitu menjadi organisasi pengelola ZIS yang dapat dipercaya, amanah, dan professional bagi seluruh nasabah. Sedangkan misi dari baznas jatim itu sendiri yakni pengoptimalan terhadap pengumpulan dana dan target ZIS dengan selalu memberikan kreasi dan inovasi baru, memaksimalkan pendistribusian dana ZIS, dan selalu mengankat tinggi-tinggi pedoman hukum syara' dalam agama islam dalam menjalankan semua yang dijalankan pada lembaga. ${ }^{22}$

Dalam manajemen dana zakat dan infak / sedekah pada BAZNAS Provinsi Jawa Timur terbagi atas pengumpulan, pendayagunaan, serta pengembangan terhadap dana zakat dan infak / sedekah. Mekanisme pengumpulan dana infak dan zakat diawali dengan implementasi perencanaan serta menyusun sasaran target penerima yang sudah direncanakan target penerima yang ingin dicapai. Selanjutnya diikuti oleh beberapa susunan program kerja untuk mengoptimalkan sasaran penerima, seperti dilakukannya sosialisasi zakat yang diadakan oleh instansi pemerimtah, instansi swasta, fundraising pada bulan Ramadhan, dan diadakannya pelatihan untuk seluruh semua amil di jawa timur guna meningkatkan kualitas SDM yang berpengaruh nantiya dalam

\footnotetext{
21 Areh G. Woodside, Case Study Research: Theory, Methods, Practice, (United Kingdom: Emerald, 2010), 8.

${ }^{22}$ Lihat profil dan sejarah Baznas Jatim di https://baznas.go.id/profil diakses tanggal 27 Februari 2021.
} 
pengelolaan dana zakat dan infak. Setelah itu dalam penghimpunan dana zakat dan infak bisa dilakukan muzakki mealui tatap muka secara langsung atupun dengan cara virtual, lalu muzakki mendapat kuitansi bukti yang menunjukkan bahwa telah menyetorkan dana zakat yang nantinya bisa difungsikan sebagai pengurang pada perhitngan pendapatan pajak. ${ }^{23}$

Pengelompokan para mustahik dibagi menjadi 3 berdasarkan beberapa kriteria oleh BAZNAS Provinsi Jawa Timur. Kepala bidang pendistribusian menyampaikan mengenai pendistribusian serta pendayagunaan dana ZIS. BAZNAS provinsi jawa timur mendahulukan penyusunan anggaran distribusi setiap program serta skala prioritas pendistribusian dari dana ZIS. ${ }^{24}$ Mekanisme pendistribusian dilakukan dengan seleksi dan survei dari kumpulan data dan hasil pencarian calon mustahiq dengan pencarian secara langsung, calon mustahiq yang mengajukan dirinya serta atas rekomendasi dari BAZNAS provinsi jatim. Kemudian, dapat mengajukan dana untuk pendistribusian kepada para mustahiq yang terpilih atas pertimbangan skala prioritas (kondisi mustahiq maupun wilayah keberadaan mustahiq). Pengelompokkan para mustahiq dibagi menjadi tiga berdasarkan dengan kriteria dari BAZNAS provinsi jawa timur, pembagian tersebut di simbolkan dengan warna, antara lain:

1. Kelompok merah merupakan kelompok dengan kriteria fakir dan orang jompo yang tidak dapat memenuhi kebutuhan hidupnya.

2. Kelompok kuning merupakan kelompok dengan kriteria gharim dan miskin yang dapat mencari nafkah, tetapi tidak penghasilannya tidak memenuhi kebutuhan sehari-hari dan tidak mampu untuk membayar hutang.

3. Kelompok hijau merupakan kelompok dengan kriteria ibnu sabil serta masih dapat memberdaya kehidupannya. ${ }^{25}$

\section{Penerapan Akuntansi Zakat di Baznas Jawa Timur}

Dalam jurnal ini, akan ditelaah hasil pembahasan tentang pengaplikasian semua kebijakan pengelolaan zakat, infaq dan shadaqah (ZIS) pada BAZ Nasional provinsi Jawa Timur, yang akan dinilai berdasar aturan yang telah dirancang untuk dana ZIS. Selain itu, juga membahas kesesuaian badan amil ini dengan peraturan yang telah dibuat. Pada table di bawah ini akan dijelaskan gimana penerapan kesesuain Undang-

\footnotetext{
${ }^{23}$ Abd. Salam Nawawi, Wawancara. (Surabaya, 23 Januari 2021), Abdussalam adalah ketua atau pimpinan Baznas Jawa Timur hingga penelitian ini dilakukan.

${ }^{24}$ Abd. Salam Nawawi, Wawancara. (Surabaya, 23 Januari 2021)

${ }^{25}$ Abd. Salam Nawawi, Wawancara. (Surabaya, 23 Januari 2021)
} 
Undang Nomor 23 Tahun 2011, Peraturan Pemerintah (PP) No. 14 Tahun 2014 \& PSAK 109 ditinjau dari BAZNAS Provinsi Jatim. ${ }^{26}$ Selanjutnya akan membahas bagaimana implementasi PSAK 109 pada BAZNAS Provinsi Jawa Timur. Berikut Table 2.1 yang menerangkan ulasan penerapan PSAK 109 :

Tabel 2.1. Ulasan Penerapan PSAK 109 pada BAZNAS Provinsi Jawa

\section{Timur}

\begin{tabular}{|c|c|c|c|}
\hline No & Keterangan & $\begin{array}{c}\text { Sesuai/Belum Sesua } \\
\text { i }\end{array}$ & $\begin{array}{c}\begin{array}{c}\text { Penerapan Akuntansi ZIS pada BAZNAS Pro } \\
\text { vinsi }\end{array} \\
\text { JATIM }\end{array}$ \\
\hline 1. & $\begin{array}{l}\text { Pengakuan } \\
\text { Dana Non- } \\
\quad \text { Halal } \\
\end{array}$ & Sesuai & $\begin{array}{c}\text { Pada BAZNAS Provinsi Jawa Timur, } \\
\text { dalam mengakui dana non- } \\
\text { halal sudah merincikan } \\
\text { secara jelas dan juga menyertkan jasa bank. }\end{array}$ \\
\hline 2. & $\begin{array}{c}\text { Pengungkapa } \\
\mathrm{n} \\
\text { ZIS }\end{array}$ & Sesuai & $\begin{array}{c}\text { Dalam pengungkapan di laporan keuangan, } \\
\text { maka akan sesuai dengan laporan } \\
\text { keuangan BAZNAS Provinsi Jatim dengan } \\
\text { PSAK } \\
109 . \\
\end{array}$ \\
\hline 3. & Penyajian ZIS & Sesuai & $\begin{array}{c}\text { Pada penyajian ZIS, BAZNAS Provinsi Jawa } \\
\text { Timur sudah membuat laporan } \\
\text { yang sesuai dengan } \\
\text { PSAK } 109 .\end{array}$ \\
\hline 4. & $\begin{array}{c}\text { Pengakuan } \\
\text { Zakat }\end{array}$ & Belum Sesuai & $\begin{array}{l}\text { a. BAZNAS Jatim mengambil bagian amil } \\
\text { dengan presentase } 10 \% \text {. } \\
\text { b. BAZNAS Jatim juga mengakui penerimaan } \\
\text { zakat sebagai modal dana zakat. } \\
\text { c. Dalam penerimaan dana zakat, badan ini } \\
\text { sudah menerapkan PSAK } 109 \text {. Tetapi, } \\
\text { belum } \\
\text { ada penerimaan secara non-kas. } \\
\text { d. Fee/upah yang diberikan diluar jatah amil, } \\
\text { tidak dibenarkan dan tidak dicatat oleh } \\
\text { BAZNAS Jatim. }\end{array}$ \\
\hline
\end{tabular}

${ }^{26}$ Rina Indrawati, "Evaluasi Penerapan Undang-Undang Pengelolaan Zakat dan Akuntansi Zakat (PSAK 109) pada Baznas Provinsi Jawa Timur", Jurnal Akuntansi AKUNESA, 4, 2(2016): 1-15. 


\begin{tabular}{c|c|c|c} 
& & & $\begin{array}{c}\text { Saat ini BAZNAS Jatim masih } \\
\text { belum menetapkan }\end{array}$ \\
5. & $\begin{array}{c}\text { Pengukuran } \\
\text { Zakat }\end{array}$ & Belum Sesuai & $\begin{array}{c}\text { pengukuran mengenai penurunan nilai } \\
\text { aset zakat non-kas. }\end{array}$ \\
\hline 6. & Pengukuran & Belum Sesuai & $\begin{array}{c}\text { Saat ini BAZNAS Jatim } \\
\text { masih belum menetapkan }\end{array}$ \\
& & pengukuran mengenai penurunan nilai \\
& & aset infaq/shadaqah. \\
\hline
\end{tabular}

Sumber: diolah dari dokumentasi dan interview

\section{Kesimpulan}

Melihat dari hasil pembahasan di atas, dapat ditarik kesimpulan, bahwa Badan Amil Zakat Nasional (BAZNAS) pada provinsi Jawa Timur berdasarkan pengawasan dana Zakat, infaq dan shadaqah (ZIS) yang berlandaskan UU Nomor 23 Tahun 2011 pada pasal 21-29 lalu pasal 31, maka terdapat masalah, pasalnya BAZNAS Provinsi Jawa Timur belum $100 \%$ berhasil menerapkan pasal 29. Berdasar dari problem tersebut badan amil zakat ini tidak menyatakan laporan hasil per-tanggungjawaban secara periodic setiap 6 bulan dan akhur tahun, lalu juga belum adanya laporan keuangan yang berasal dari akuntan public. Dengan adanya PSAK No. 109, beberapa kebijakan yang dibuuat oleh BAZNAS Jawa Timur masih belum terealisasi. Alasan terhadap masalah tersebeut, dikarenakan kurang efektifnya cara pengelolaan dana zakat, infaq dan shadaqah serta kurangnya sumber daya insani yang memadai pada badan usaha tersebut.

Dengan melihat kesimpulan diatas, penulis berharap agar BAZNAS Provinsi Jawa Timur bisa mengatasi masalah tersebut. Dengan cara, melatih dan menambah SDM yang berkualitas terutama dalam bagian akuntansi dan keuangan. Lalu membenahi sistem informasi pada bagian akuntan. Pada pemebenahan system informasi ini lah yang menjadi saran penulis agar Badan Amil Zakat Nasional (BAZNAS) Provinsi Jawa Timur lebih bisa mengelola dana ZIS. Dan juga penulis berharap agar badan amil zakat ini bisa menerapkan secara lebih baik lagi PSAk 109, UU. No. 23 Tahun 2011 dan PP. No. 14 Tahun 2014.

\section{Daftar Pustaka}

Afiyana F.I. dkk., "Tantangan Pengelolaan Dana Zakat di Indonesia dan Literasi Zakat", Akuntebel, 1,6(2019). 
Areh G. Woodside, Case Study Research: Theory, Methods, Practice, (United Kingdom: Emerald, 2010.

Aziz, M. Wahib. "Wakaf Tunai dalam Perspektif Hukum Islam", International Journal Ihya' al-Din, 19, 1(2017).

Baridwan, Zaki. Intermediate Accounting. Yogyakarta: BPFE, 2008.

Bastiar, Yandi; Efri Syamsul Bahri, "Model Pengukuran Kinerja Lembaga Zakat di Indonesia", Ziswaf: 6, 1(2019).

Baznas, Indeks Literasi Zakat: Teori dan Konsep. Jakarta: Pusat Kajian Strategis Badan AMil Zakat Nasional, 2019.

Djarwanto, Pokok-Pokok Analisa Laporan Keuangan. Yogyakarta: BPFE, 1997.

DSAK IAI. Pernyataan Standar Akuntansi Keuangan No. 109 Akuntansi Zakat dan Infak/ Sedekah. Jakarta: IAI, 2011.

Hamid, Farid; Heri Budianto, Ilmu Komunikasi: Sekarang dan Tantangan Masa Depan. Jakarta: Kencana Prenada Media Group, 2011.

Hery, Teori Akuntansi. (Jakarta: Kencana Prenada Media Group, 2009).

Indrawati, Rina. "Evaluasi Penerapan Undang-Undang Pengelolaan Zakat dan Akuntansi Zakat (PSAK 109) pada Baznas Provinsi Jawa Timur", Jurnal Akuntansi AKUNESA, 4, 2(2016).

Moleong, Lexy J. Metodologi Penelitian Kualitatif. Bandung: Remaja Rosdakarya, 2014.

Nasifudin, Muhammad. “Konsep Sistem Pengelolaan Zakat di Indonesia Pengentas Kemiskinan Pendekatan Sejarah", JE: Jurnal Ekonomi Syariah Indonesia, 5,2(2015).

Permatasari, Carolina Lita; Heri yanto; Widyanto, "Penerimaan Pernyataan Standar Akuntansi Keungan oleh Pengelola Keuangan Yayasan Pendidikan: Analisis Technology Acceptance Model", JEE: Journal of Economic Education, 5, 1(2016).

Rahman, Taufikur. "Akuntansi Zakat, Infak dan Sedekah (PSAK 109) : Upaya Peningkatan transpran Akuntabilitas Organisasi Pengelola Zakat (OPZ)", Muqtasid: Journal of Islamic Economics and Baniking, 6,1(2015).

Rahman, Taufikur. “Akuntansi Zakat, Infak dan Sedekah (PSAK 109), 154.

Ramadhan, Muhammad Rheza. "Integrasi Pajak dan Zakat di Indonesia", Islamiconomic: Jurnal Ekonomi Islam, 8, 1(2017).

Shahnaz, Sabrina. "Penerapan PSAK No. 109 tentang Pelaporan Keuangan Akuntansi Zakat, Infaq/sedekah pada Badan Amil Zakat Provinsi Sulawesi Utara", Jurnal Emba: Jurnal Rset Ekonomi, Manajemen, Bisnis dan Akuntansi, 3,4(2015).

Sugiyono, Metode Penelitian Kuantitatif Kualitatif dan $R \in \mathcal{E}$ (Bandung: Alfabeta, 2014. 
Yudha, Ana Toni Roby Candra; Nurul Lathifah, "Productive Zakat as a Fiscal Element for the Development and Empowerment of Micro Enterprises in East Java Province", International Conference of Zakat, https://doi.org/https://doi.org/10.37706/iconz.2018.123.

Yusfiarto, Rizaldi; Ananda Setiawan; Spty Setia Nugraha, “Literacy and Intention to Pay Zakat: a Theory Planned Behavior View Evidence from Indonesian Muzakki", International Journal of Zakat, 5,1(2020). https://baznas.go.id/profil.

Abd. Salam Nawawi, Wawancara. 